\title{
Association of overweight and obesity with psychological problems in school children
}

\author{
Josefa Canals-Sans ${ }^{1}$, Ainara Blanco-Gómez ${ }^{1}$, Verónica Luque ${ }^{2}$, Natàlia Ferré2 , Paula Morales- \\ Hidalgo ${ }^{1}$, Ricardo Closa-Monasterolo $\mathrm{o}^{2}$ y Joaquín Escribano ${ }^{2}$ \\ ${ }^{1}$ CRAMC, Universidad Rovira i Virgili, Tarragona, Spain. \\ ${ }^{2}$ CRAMC, Universidad Rovira i Virgili, Reus, Spain.
}

\begin{abstract}
This study researched the relationship between overweight/obesity and psychological problems in children, emphasizing the interactive effects of gender, body dissatisfaction (BD) and socioeconomic status (SES). A total of 515 children with a mean age of 8.5 from Reus (Spain) were measured for weight and height and answered the Figure Rating Scale. Parents completed the Child Behavior Checklist. Children with obesity showed the greatest BD, were significantly more withdrawn/depressed (12.9\% versus 3.2\%) and had more aggressive behavior (9.7\% versus $1.6 \%)$ than normal weight children $(p=.04)$. The overweight and overweight/obese groups showed more somatic complaints than normal weight children $(17.3 \%$ and $19.4 \%$ versus $9.4 \% ; p=$ .007). The internalizing dimension, together with BD, was significantly related to the overweight/obese condition. Specifically, children with somatic complaints had a 2.64-fold increased probability of being overweight/obese. However, BD and SES did not mediate the relationship between internalizing problems and obesity. The study results support the relationship between obesity and internalizing problems in childhood.
\end{abstract}

Keywords: Psychopathology; obesity; emotional problems; children.

Asociación entre el sobrepeso y la obesidad con los problemas psicológicos en escolares

Resumen: El presente estudio investiga la relación entre sobrepeso/obesidad y problemas psicológicos en escolares, evaluando la interacción del género, insatisfacción corporal (IC) y nivel socioeconómico (NSE). Un total de 515 niños de 8.5 años (Reus, España) fueron pesados, medidos y respondieron la Figure Rating Scale. Los padres completaron el Child Behaviour Checklist. Los niños obesos presentaron más IC, mostraron significativamente más retraimiento/depresión (12.9\% versus 3.2\%) y conducta agresiva $(9.7 \%$ versus $1.6 \%$ ) que de los de peso normal $(p=.04)$. Los niños con sobrepeso y sobrepeso/obesidad presentaron más quejas somáticas que los de peso normal (17.3\% y $19.4 \%$ versus $9.4 \% ; p=.007)$. La dimensión de problemas interiorizados, junto a la IC, estuvo significativamente relacionada con el sobrepeso/obesidad. Específicamente, los niños con quejas somáticas tuvieron 2.64 veces mayor probabilidad de ser obesos. No obstante, la IC y el NSE no mediaron la relación entre problemas internalizados y obesidad. Los resultados apoyan la relación entre obesidad y los problemas interiorizados en edades tempranas.

Palabras clave: Psicopatología; obesidad; problemas emocionales; niños.

\section{Introduction}

Obesity is considered an eating behavior disorder within the broad range of weight-related and feeding

Recibido: 20 de septiembre 2017; aceptado el 10 de febrero 2018. Corresponding author: Josefa Canals Sans, Rovira i Virgili University, Tarragona, Spain. email address: josefa.canals@urv.cat.

Funding: This work was partially funded by the Spanish Ministry of Science and Innovation in the EUROSALUD 2008 call (EUS200803584). disorders. The etiology of obesity can be understood within a biopsychosocial model that involves multiple factors, such as early-life diet, socio-economic situation, dietary habits, sedentary lifestyle, genetic predisposition, physiological conditions and psychological state (Braet, 2005; Brands, Demmelmair \& Koletzko, 2014; Robinson et al., 2015; Spruijt-Metz, 2011; Vámosi, Heitmann, \& Kyvik, 2010). The association between psychological problems and being overweight/obese appears to emerge early in life and both are significant public health problems. 
Between 10 and $20 \%$ of children suffer from psychological problems (Belfer, 2008; Kieling et al., 2011). Overweight and obesity in children range from approximately $10 \%$ in countries like Denmark to $30 \%$ in Mediterranean countries (Manios \& Costarella, 2011). The relationship between a high BMI and psychological problems has been described for as early as 3 years of age (Griffiths, Dezateux, \& Hill, 2011). Although the most related problems seem to be emotional, such as anxiety and depression disorders (Brumpton, Langhammer, Romundstad, Chen, \& Mai, 2013; Chiang, Huang, Lo, Lee, \& Wahlqvist, 2013; Esposito et al., 2014; Faith et al., 2011; Morrison, Shin, Tarnopolsky \& Taylor, 2015; Mühlig, Antel, Föcker, \& Hebebrand, 2016; Roberts \& Duong, 2016), age, gender, the clinical or community sample, and cultural differences may explain the association with other psychological problems (Burke \& Storch, 2015; Gibson et al., 2008; Griffiths et al., 2011; Sawyer et al. 2006; Seyedamini, Malek, Ebrahimi-Mameghani, \& Tajik, 2012; Ter Bogt et al., 2006; Tso, Rowland, Toumbourou, \& Guadagno, 2017). In contrast, other authors have not found a relationship between psychopathology and overweight/ obesity (Freitas-Rosa, Goncalves, \& Antunes, 2014), or the differences were so small that many associations became non-significant after adjusting for a range of sociodemographic covariates (Sawyer et al., 2006). It is currently unclear whether psychological problems are the cause or the consequence of childhood obesity or whether common factors promote both obesity and psychiatric disturbances in susceptible children and adolescents (Manna, Mamun, Doi, \& Clavarino, 2016; Rankin et al., 2016). In any case, determining the mutual influence of these factors could be essential for designing effective intervention programs for obesity, since these programs often include training in central executive functions and emotional regulation (Segura et al., 2017).

The association between obesity and psychological problems may be mediated by several factors (Rankin et al., 2016). Specifically, the association between obesity and depression could differ in relation to gender and age (Anderson, Cohen, Naumova, \& Must, 2006; Chiang et al., 2013; Pervanidou \& Chrousos, 2011), as it is most problematical among adolescent females (Blaine, 2008; Mühlig et al., 2016; Rofey et al., 2009; Vámosi et al., 2010). Obesity may increase the risk of depression through stigmatization, body image dissatisfaction (BD), effects of dieting, and impairments in physical health and functioning. In a study conducted with children and adolescents from 9 to 16 years old, overweight/obese participants showed higher BD, lower academic and corporal self-esteem, and higher levels of anxiety (Cebolla, Baños, Botella, Lurbe, \& Torró, 2011). Among these factors, BD has been identified as the psychological correlate of obesity most related to depression, especially among women (Al Mamun et al. 2007; Ter Bogt et al. 2006; Weinberger, Kerstingd, Riedel-Hellerb, \& Luck-Sikorskia, 2016). In addition, it can work in the opposite direction because depression can increase the risk of obesity through changes in lifestyle and direct biochemical effects on appetite regulation, so that the person eats to regulate their moods (Aparicio, Canals, Voltas, Hernández, \& Arija, 2016; Vannucci et al., 2013). Byrne, O’Brien-Simpson, Mitchell, and Allen (2015) suggested a model whereby inflammation and obesity are outcomes of adolescent depression. Rises in sex hormones during puberty increase the risk of depression for females, which can lead to obesity, which in turn increases inflammation levels. However, some authors have found that there is no relationship between emotional disturbance and obesity in young children and adolescents (Drukker, Wojciechowski, Feron, Mengelers, \& Van Os, 2009). In addition to emotional problems, behavioral and neurodevelopmental disorders have also been shown to have a relationship with obesity, or have been considered predictors of weight gain (Dahlgren \& Björk 2014; Khalife et al. 2014; Korczak, Lipman, Morrison, Duku, \& Szatmari, 2014; Mallan et al., 2017; Wentz, Björk, \& Dahlgren et al., 2017). Among these disorders, meta-analytic evidence shows a significant association between ADHD and obesity, regardless of possible confounding factors such as other psychiatric comorbidities (Cortese \& Tessari, 2017). This relationship has been found already in the preschool age by Perez-Bonaventura, Granero, \& Ezpeleta (2015), who showed that a higher BMI at the age of 3 years was predictive of hyperactivity and ADHD symptoms at the age of 4 years. Several mechanisms may explain this association, highlighting the role, among others, of abnormal eating patterns secondary to food cue disorders and difficulties in inhibitory control over food, sedentary lifestyle and possible common genetic alterations (Van Den Akker, Stewart, Antoniou, Palmberg, \& Jansen, 2014; Cortese \& Tessari, 2017).

Another factor that is related to the increasing prevalence of obesity and psychological problems is a lower socioeconomic position. The systematic review carried out by Chung et al. (2016) showed that in economically advanced countries, socioeconomic inequalities are positively related to child and adolescent obesity prevalence. In Italian children aged 6 to 8 years old, Grassi et al. (2016) also found that being overweight 
was associated with parents' lower level of education and employment. However, socioeconomic status (SES) is a significant risk factor for negative mental development due to economic stress, chaos in the home, parent depression, conflicts between parents, and parenting practices (Devenish, Hooley, \& Mellor, 2017).

The aim of the present study was to investigate the association between overweight/obesity and psychological problems in Spanish schoolchildren in middle childhood. We report cross-sectional data on this relationship by focusing on the interactive effect of gender, BD and socioeconomic status (SES). Our hypothesis is that there is a relationship between a high BMI and psychological problems, and that internalizing problems are associated more with obesity than externalizing problems, as previously found in adolescents. This relationship could be mediated by BD and SES.

\section{Methods}

\section{Study population}

Five hundred and fifteen children (250 boys and 265 girls) in the second to fourth grades from twenty randomly selected state $(80 \%)$ and private $(20 \%)$ primary schools in Reus (Spain) participated in the study after their parents signed the informed consent form. A potential population of 1623 students were invited to participate after permission was obtained from the Education Department to access schools. Of the 515 children, $20 \%$ were from families with low SES, $53 \%$ were from families with medium SES, and $23 \%$ were from families with high SES. The mean age of the participants was $8.54( \pm .64)$ with a minimum age of 6.5 and a maximum of 10 years.

The sample was distributed into three groups: overweight $(n=149)$, obese $(n=37)$ and normal weight $(n=316)$. Underweight children were excluded from the analyses.

\section{Measures}

Child Behavior Checklist 6-18 (CBCL/6-18; Achenbach \& Rescorla 2001). Parents completed the Spanish version of the CBCL, which has 113 items of behavioral problems with 3 possible answers on a Likert scale that provided scores for eight scales; anxious/ depressed, withdrawn/depressed, somatic complaints, social problems, thought problems, attention problems, rule-breaking behavior and aggressive behavior. The first three scales build up the internalizing dimension, the last two scales make up the externalizing dimension and the sum of scores for all the problem items make up the total psychological problems dimension. We used the CBCL scale scores for multicultural normative samples to classify the raw scores into normal, borderline and clinical categories. The internal consistency (Cronbach's alpha) for this sample was .94 for the full scale.

Anthropometric data. Weight and height were individually measured with a calibrated scale and a stadiometer (SECA 702 \& SECA 2014, respectively), with the children standing in light clothing and barefoot in an individual room prepared at school for this purpose. Body Mass Index (BMI) was calculated as weight in kilograms divided by the square of height in meters. In order to be consistent with international research, as proposed by the International Obesity Task Force, age and sex specific cut-off points for BMI for overweight and obesity in children were estimated using dataset specific centiles linked to adult cut off points $\left(25 \mathrm{~kg} / \mathrm{m}^{2}\right.$ for overweight and $30 \mathrm{~kg} / \mathrm{m}^{2}$ for obesity; Cole, Bellizzi, Flegal, \& Dietz, 2000).

Body Image perception. Children's own body image perception was assessed with the Figure Rating Scale (FRS; Eckstein et al., 2006). The FRS shows seven schematic sketches of children that can be used to examine the boys' and girls' ideas of their current and desired body size. The middle image in each series of sketches represents a child in the $50^{\text {th }} \mathrm{BMI}$ percentile; the other sketches are not tied to particular BMI percentile categories. These scales have been proven to be highly reliable (Eckstein et al., 2006). Therefore, body image dissatisfaction in children was measured by the discrepancy between the two figures chosen, and was dichotomized into being satisfied or being dissatisfied with their body image. Children with normal weight who were dissatisfied with their body image because they wanted to be fatter were excluded from the statistical analyses. The internal consistency for the items about current and desired body size in this sample was .33.

Socioeconomic status (SES). Parents were asked about their employment and the Classification of Occupations of the Statistical Institute of Catalonia (CCO-94/ca), Decree 98/1995) was used to code the information and define their socioeconomic status (SES). The SES was recoded into low, middle and high status.

\section{Statistical Analyses}

The statistical analyses were performed using IBM SPSS version 20.0 (Armonk, NY: IBM Corp.). EPIDAT 3.1 (Xunta de Galicia, Spain) was also used 
to perform the two-proportion z-test and calculate the possible differences in psychological problems within each sociodemographic variable, BMI category (normal weight, overweight and obese) and body image. We performed a Chi-square test to compare groups according to anthropometric, psychopathological and sociodemographic variables. We used logistic regression models with the stepwise method to determine the associations between psychological problems as a predictor variable and BMI status as an outcome variable. For logistic regression, the BMI status was determined by two categories: normal weight or obesity (overweight, including obesity). All the CBCL scores were dichotomized into two categories: normal or disordered (borderline, including clinical). We entered the eight CBCL scales into a model (Pearson correlations between the CBCL scales showed there was no collinearity) and adjusted for age, gender, socio-economic status and body image dissatisfaction. Collinearity was found between the total problems dimension and both the internalizing $(r=.61)$ and externalizing dimensions $(r=.65)$. We performed logistic regression models for each single dimension as psychopathological predictors. A series of regression analyses called mediational models were applied to determine the possible mediator variables of the relationships found. Mediation analyses were carried out according to Baron and Kenny's criteria (Allen, Byrne, Blair \& Davis, 2006; Preacher \& Hayes, 2008). These criteria require that 1) the independent variable predicts the mediator, 2) the mediator predicts the dependent variable, and 3) a significant relationship between the independent and dependent variable becomes weaker when the effects of the mediator are considered.

\section{Results}

Association between anthropometric status, sociodemographic variables and psychological problems

As can be seen in Table 1, there were no significant differences between gender, age, socioeconomic level or anthropometric status. Significant differences were found between anthropometric status and body image dissatisfaction. Overweight and obese children were more dissatisfied than normal-weight children $\left(\chi^{2}=\right.$ $18.79, p<.01 ; \chi^{2}=32.84, p<.01$, respectively), and obese children were more dissatisfied than overweight children $\left(\chi^{2}=11.32, p<.01\right)$.

Table 2 shows the relationship between psychological problems and anthropometric status. Obese children showed both more withdrawn/depressed and aggressive behavior in the clinical range $(12.9 \%$ and $9.7 \%$ respectively) than normal-weight children $(3.2 \%$ and $1.6 \%$, respectively) $\left(\chi^{2}=10.08, p=.04\right.$ and $\chi^{2}=10.20, p$ $=.04$ ). When obesity including overweight (overweight/ obese) was considered, somatic complaints in the clinical range $(9.1 \%)$ were also significantly higher $\left(\chi^{2}=7.82, p\right.$ $=.02)$ in relation to normal weight children $(3.9 \%)$.

When CBCL scores were dichotomized into normal or disordered (borderline, including clinical range), overweight and overweight/obese children had more somatic complaints $(17.3 \%$ and $19.4 \%$, respectively) than normal-weight children $(9.4 \%)\left(\chi^{2}=6.01, p=.01\right.$ and $\left.\chi^{2}=7.21, p=.007\right)$. In addition, social problems were higher in overweight $(9.0 \%)$ and overweight/obese $(6.5 \%)$ children than normal-weight children $(4.2 \%)\left(\chi^{2}\right.$ $=4.26, p=.039$ and $\chi^{2}=3.94, p=.042$, respectively). Lastly, obese children also showed a significantly higher

Table 1. Sociodemographic characteristics by anthropometric status

\begin{tabular}{|c|c|c|c|c|c|}
\hline & & $\begin{array}{c}\text { Normal Weight } \\
n(\%)\end{array}$ & $\begin{array}{c}\text { Overweight } \\
n(\%)\end{array}$ & $\begin{array}{c}\text { Obesity } \\
n(\%)\end{array}$ & $\begin{array}{l}\chi^{2} \\
(p)\end{array}$ \\
\hline \multirow[t]{2}{*}{ Gender } & Male & $157(49.7)$ & $70(47.0)$ & $18(48.7)$ & .30 \\
\hline & Female & $159(50.3)$ & $79(53.0)$ & $19(51.4)$ & $(.86)$ \\
\hline \multirow[t]{3}{*}{ School grade } & 2 nd & $97(30.7)$ & $38(25.5)$ & $10(27.0)$ & 3.76 \\
\hline & $3 \mathrm{rd}$ & $152(48.1)$ & $85(57.1)$ & $21(56.8)$ & $(.44)$ \\
\hline & 4 th & $67(21.2)$ & $26(17.4)$ & $6(16.2)$ & \\
\hline \multirow[t]{3}{*}{ Socioeconomic status } & Low & $86(28.6)$ & $35(26.3)$ & $13(41.9)$ & 10.62 \\
\hline & Average & $134(44.5)$ & $71(53.4)$ & $15(48.4)$ & $(.10)$ \\
\hline & High & $81(26.9)$ & $27(20.3)$ & $3(9.7)$ & \\
\hline \multirow[t]{2}{*}{ Body image } & Dissatisfaction & $107(44.0)$ & $95(66.9)$ & $35(94.6)$ & 43.37 \\
\hline & Satisfaction & $136(56.0)$ & $47(33.1)$ & $2(5.4)$ & $(<.01)$ \\
\hline
\end{tabular}

Note. $p \leq .05$ 
Table 2. Psychological characteristics by anthropometric status

\begin{tabular}{|c|c|c|c|c|c|c|c|}
\hline & & $\begin{array}{c}\text { Normal } \\
\text { Weight }^{\text {a }} \\
n(\%)\end{array}$ & $\begin{array}{c}\text { Overweight } \\
n(\%)\end{array}$ & $\begin{array}{c}\text { Obesity } \\
n(\%)\end{array}$ & $\begin{array}{l}\chi^{2} \\
(p)\end{array}$ & $\begin{array}{c}\text { Overweight } \\
\text { Obesity }^{\mathrm{b}} \\
n(\%)\end{array}$ & $\begin{array}{c}\chi^{2} \\
(p)^{\mathrm{ab}}\end{array}$ \\
\hline \multirow[t]{3}{*}{ Anxiety/Depressed } & Normal & $272(87.7)$ & $127(88.2)$ & $28(90.3)$ & 4.73 & $155(88.5)$ & 2.20 \\
\hline & Borderline & $21(6.8)$ & $14(9.7)$ & $1(3.2)$ & $(.32)$ & $15(8.6)$ & $(.33)$ \\
\hline & Clinical & $17(5.5)$ & $3(2.1)$ & $2(6.5)$ & & $5(2.9)$ & \\
\hline \multirow[t]{3}{*}{ Withdrawn /Depressed } & Normal & $273(88.1)$ & $124(86.1)$ & $27(87.1)$ & 10.08 & $151(86.3)$ & 1.09 \\
\hline & Borderline & $27(8.7)$ & $15(10.4)$ & $0(0.0)$ & $(.04)$ & $15(8.6)$ & $(.58)$ \\
\hline & Clinical & $10(3.2)$ & $5(3.5)$ & $4(12.9)$ & & $9(5.1)$ & \\
\hline \multirow[t]{3}{*}{ Somatic complaints } & Normal & $281(90.6)$ & $119(82.7)$ & $25(80.6)$ & 7.99 & $144(82.3)$ & 7.89 \\
\hline & Borderline & $17(5.5)$ & $12(8.3)$ & $3(9.7)$ & $(.09)$ & $15(8.6)$ & $(.02)$ \\
\hline & Clinical & $12(3.9)$ & $13(9.0)$ & $3(9.7)$ & & $16(9.1)$ & \\
\hline \multirow[t]{3}{*}{ Social problems } & Normal & $297(95.8)$ & $131(91.0)$ & $29(93.5)$ & 5.50 & $160(91.4)$ & 4.42 \\
\hline & Borderline & $8(2.6)$ & $9(6.2)$ & $2(6.5)$ & $(.24)$ & $11(6.3)$ & $(.11)$ \\
\hline & Clinical & $5(1.6)$ & $4(2.8)$ & $0(0.0)$ & & $4(2.3)$ & \\
\hline \multirow[t]{3}{*}{ Thought problems } & Normal & $295(95.1)$ & $138(95.8)$ & $28(90.3)$ & 5.75 & $166(94.9)$ & 1.48 \\
\hline & Borderline & $7(2.3)$ & $2(1.4)$ & $0(0.0)$ & $(.22)$ & $2(1.1)$ & $(.48)$ \\
\hline & Clinical & $8(2.6)$ & $4(2.8)$ & $3(9.7)$ & & $7(4.0)$ & \\
\hline \multirow[t]{3}{*}{ Attention problems } & Normal & $267(86.1)$ & $122(84.7)$ & $26(83.9)$ & 1.55 & $148(84.6)$ & .31 \\
\hline & Borderline & $27(8.7)$ & $12(8.3)$ & $4(12.9)$ & $(.82)$ & $16(9.1)$ & $(.86)$ \\
\hline & Clinical & $16(5.2)$ & $10(7.0)$ & $1(3.2)$ & & $11(6.3)$ & \\
\hline \multirow[t]{3}{*}{ Rule breaking behavior } & Normal & $290(93.5)$ & $135(93.7)$ & $30(96.8)$ & 3.15 & $165(94.3)$ & 1.74 \\
\hline & Borderline & $13(4.2)$ & $3(2.1)$ & $1(3.2)$ & $(.48)$ & $4(2.3)$ & $(.42)$ \\
\hline & Clinical & $7(2.3)$ & $6(4.2)$ & $0(0.0)$ & & $6(3.4)$ & \\
\hline \multirow[t]{3}{*}{ Aggressive behavior } & Normal & $277(89.4)$ & $122(84.7)$ & $27(87.1)$ & 10.20 & $149(85.1)$ & 7.66 \\
\hline & Borderline & $28(9.0)$ & $14(9.7)$ & $1(3.2)$ & (.04) & $15(8.6)$ & $(.02)$ \\
\hline & Clinical & $5(1.6)$ & $8(5.6)$ & $3(9.7)$ & & $11(6.3)$ & \\
\hline \multirow[t]{3}{*}{ Internalizing } & Normal & $219(70.6)$ & $92(63.9)$ & $19(61.3)$ & 4.01 & $111(63.4)$ & 2.75 \\
\hline & Borderline & $36(11.6)$ & $21(14.6)$ & $3(9.7)$ & $(.41)$ & 24 (13.7) & $(.25)$ \\
\hline & Clinical & $55(17.8)$ & $31(21.5)$ & $9(29.0)$ & & $40(22.9)$ & \\
\hline \multirow[t]{3}{*}{ Externalizing } & Normal & $250(80.6)$ & $111(77.1)$ & $24(77.4)$ & 1.78 & 135 (77.2) & 1.29 \\
\hline & Borderline & $28(9.0)$ & $14(9.7)$ & $2(6.5)$ & $(.78)$ & $16(9.1)$ & $(.53)$ \\
\hline & Clinical & $32(10.4)$ & $19(13.2)$ & $5(16.1)$ & & $24(13.7)$ & \\
\hline \multirow[t]{3}{*}{ Total Problems } & Normal & $257(82.9)$ & $114(79.2)$ & $21(67.8)$ & 5.85 & 135 (77.2) & 3.43 \\
\hline & Borderline & $28(9.0)$ & $12(8.3)$ & $5(16.1)$ & $(.21)$ & 17 (9.7) & $(.18)$ \\
\hline & Clinical & $25(8.1)$ & $18(12.5)$ & $5(16.1)$ & & $23(13.1)$ & \\
\hline
\end{tabular}

Note. $p \leq .05$

prevalence of total psychological problems $(32.2 \%)$ than normal-weight children $\left(17.1 \% ; \chi^{2}=4.30, p<.05\right)$.

\section{Association between psychological problems and overweight/obesity: multivariate models}

The logistic regression model analyzed the relationships of the eight $\mathrm{CBCL}$ scales (borderline including clinical) with anthropometric status (overweight/obesity) after adjustment had been made for $\mathrm{BD}$ and sociodemographic variables (see table 3 ).
Those children with somatic complaints showed a 2.64fold increased probability of being overweight/obese. Body image dissatisfaction was also related to being overweight/obese (OR 3.02). These two factors explained $12.6 \%$ of the variance of being overweight/obese.

Three logistic regression models were performed to analyze the separate association of each CBCL dimension (borderline including clinical) with anthropometric status. Only the internalizing dimension was significantly related to the condition overweight/obese. Having internalizing problems and body dissatisfaction 
Table 3. Significant logistic regression models: the effect of psychological problems on being overweight/obese.

\begin{tabular}{|c|c|c|}
\hline Model 1 & Odds ratio $(95 \% \mathrm{CI})$ & $p$ \\
\hline Body image dissatisfaction (Yes) & $3.02(1.94$ to 4.70$)$ & $<.01$ \\
\hline Somatic complaints (borderline plus clinical) & 2.64 (1.39 to 5.02$)$ & $<.01$ \\
\hline
\end{tabular}

Model parameters: $p=.002 ; x^{2} 2.383=37.53 ; r^{2}$ Nagelkerke $100=12.6 \%$.

Variables entered in the model: age, gender, socio-economic status, body image dissatisfaction and eight CBCL scales.

\begin{tabular}{|c|c|c|}
\hline Model 2 & Odds ratio $(95 \% \mathrm{CI})$ & $p$ \\
\hline Body image dissatisfaction (Yes) & $3.02(1.94$ to 4.70$)$ & $<.01$ \\
\hline Internalizing problems (borderline plus clinical) & $1.60(1.02$ to 2.52$)$ & $<.05$ \\
\hline
\end{tabular}

Model parameters: $p=.04 ; x^{2} 2.383=32.60 ; r^{2}$ Nagelkerke $100=11 \%$.

Variables entered in the model: age, gender, socio-economic status, body image dissatisfaction and total problems dimension.

Table 4. Results $(\beta)$ of regression analyses of mediation.

\begin{tabular}{|c|c|c|c|c|c|}
\hline \multicolumn{2}{|c|}{ Mediational chains (IV $\rightarrow$ MV $\rightarrow$ DV) } & \multirow{2}{*}{$\frac{\mathrm{IV} \rightarrow \mathrm{MV}}{1.69^{*}}$} & \multirow{2}{*}{$\frac{\mathrm{MV} \rightarrow \mathrm{DV}}{3.37^{* * *}}$} & \multirow{2}{*}{$\frac{\mathrm{IV} \rightarrow \mathrm{DV}}{\mathrm{ns}}$} & \multirow{2}{*}{$\begin{array}{c}\mathrm{IV}+\mathrm{MV} \rightarrow \mathrm{DV} \\
\mathrm{MV}=3.29^{* * *} \\
\mathrm{IV}=\mathrm{ns}\end{array}$} \\
\hline Model A & $\begin{array}{l}\text { Internalizing problems } \rightarrow \text { body } \\
\text { image dissatisfaction } \rightarrow \text { obesity }\end{array}$ & & & & \\
\hline Model B & $\begin{array}{l}\text { Internalizing problems } \rightarrow \text { socio-economic } \\
\text { status } \rightarrow \text { obesity }\end{array}$ & $.48 * *$ & $.61^{*}$ & ns & $\begin{array}{c}\mathrm{MV}=\mathrm{ns} \\
\mathrm{IV}=1.57^{*}\end{array}$ \\
\hline Model C & $\begin{array}{l}\text { Body image dissatisfaction } \rightarrow \text { internalizing } \\
\text { problems } \rightarrow \text { obesity }\end{array}$ & $1.69 *$ & ns & $3.37 * * *$ & $\begin{array}{c}\mathrm{MV}=\mathrm{ns} \\
\mathrm{IV}=3.29 * * *\end{array}$ \\
\hline Model D & $\begin{array}{l}\text { Obesity } \rightarrow \text { body image } \\
\text { dissatisfaction } \rightarrow \text { internalizing problems }\end{array}$ & $3.37 * * *$ & $1.69 *$ & ns & $\begin{array}{l}\mathrm{MV}=1.75^{*} \\
\mathrm{IV}=\mathrm{ns}\end{array}$ \\
\hline
\end{tabular}

Note. $\mathrm{IV}=$ independent variable; $\mathrm{MV}=$ mediator variable; $\mathrm{DV}=$ dependent variable. $* p<0,05 * * p<0.01, * * * p<0.001$.

increased the probability of overweight/obesity 1.6-fold and 3.0-fold, respectively.

Considering the associations found and the previous literature, we used mediational models to test the relationship of the directionality between obesity (including overweight), internalizing problems (borderline including clinical), BD and SES (Table 4). Obesity was bidirectionally related to $\mathrm{BD}$ but $\mathrm{BD}$ was not related to internalizing problems. Although some significant relationships were found, the analyses did not meet sufficient statistical criteria to support any mediational model. Thus, model A found a significant relationship between internalizing problems (independent variable; IV) and BD (mediational variable; MV) but no relationship was found between IV and obesity (dependent variable; DV). The same situation was found in model $\mathrm{D}$, when the $\mathrm{BD}$ was considered a mediator between obesity (IV) and internalizing problems (DV). However, when the SES was explored as mediator between internalizing problems (IV) and obesity (DV), the model (B) was not significant, although SES was related to internalizing problems and obesity. Model C showed that internalizing problems did not mediate the relationship between $\mathrm{BD}$ and obesity.

\section{Discussion}

This study supports a relationship between psychopathology and obesity in school-aged children. Obese children showed a higher prevalence of total psychological problems (borderline including clinical) than normal-weight children, in agreement with other studies with clinical and non-clinical samples (Esposito et al., 2014; Griffiths et al., 2011; Gibson et al., 2008; Rankin et al., 2016; Sawyer et al., 2006; Seyedamini et al., 2012; Vila et al., 2004). Specifically, among the different scales of CBCL/6-18, somatic complaints, withdrawn/ depressed, aggressive behavior and social problems were significantly associated with the overweight and/ or obesity status. When we adjusted these relationships for sociodemographic variables, being overweight/ obese was associated with somatic complaints and also with the internalizing problems dimension. In this regard, it should be noted that somatizations are part of internalizing problems and are also associated with other internalizing problems, such as depression and anxiety (Ask, Waaktaar, Seglem, \& Torgersen, 2016; Campo, 2012; Shanahan et al., 2015). While our study found a higher prevalence of withdrawn/depressed in 
obese children, like other authors (Erickson, Robinson, Haydel, \& Killen, 2000; Esposito et al., 2014; Morrison et al., 2015; Rankin et al., 2016), our findings did not support a higher prevalence of anxiety problems as shown in other studies (Chiang et al., 2013; Goldfield et al., 2010; Esposito et al., 2014). This association might be observed later in life, as some research has found that symptoms of anxiety or depression during childhood and adolescence predict later obesity (Aparicio et al., 2013; Blaine, 2008; Mannan et al., 2016; Robert \& Duong, 2016; Rofey et al., 2009; Vámosi et al., 2010). It is also possible that at early ages, the manifestations of internalizing problems are based more on somatic complaints. One possible explanation of the relationship between internalizing problems, somatic complaints and high BMI is that these children do not have adequate strategies to regulate emotional distress, which they express through somatizations or they may eat to stay calm. Furthermore, somatization in children may limit their activities, such as leading to a reduction in physical activity, which is a contributory factor to high BMI. The relationship found between social problems and obesity/ overweight could be interpreted as a consequence of the limitations of the BMI; obese children may be less accepted by their peers, they play less group sport, which is a normal activity for children of these ages, and they also have lower body satisfaction that interferes with self-esteem and social relationships. In this sense, AlAgha, Al-Ghamdi, and Halabi (2016) studied children with a mean age of 10 years in Western Saudi Arabia and found that a higher BMI was associated with social problems related to the difficulty of doing things that other children could do. In early stages of development (children of 3.5 to 5 years old), other authors also found more peer relationship problems in cases of higher BMI (Griffits et al. ,2011; Mallan et al., 2017; PerezBonaventura et al., 2015).

The mediational models did not show that the relationship between internalizing problems and obesity was mediated by $\mathrm{BD}$ or SES, although both variables were associated with obesity. It is probable that the relationship between internalizing problems and obesity is influenced by the interaction of multiple variables. The most significant relationship was found between $\mathrm{BD}$ and obesity, as other authors have reported for both adolescents (Doyle, Le Grange, Goldschmidt, \& Wilfley, 2007; Babió, Arija, Sancho, \& Canals, 2008) and children. This indicates that overweight and obese children were significantly more dissatisfied with their body image than normal-weight children (Allen et al., 2006; Goldfield et al., 2010). In agreement with Mond van den Berg, Boutelle, Hannan, and Neumark-
Sztainer (2011), we found a significant relationship between internalizing problems and BD. However, the relationship between low SES and obesity was consistent with other authors (Chung et al., 2016; Grassi et al., 2016) and, as reported in Tandon et al. (2012), could be indirectly due to parenting practices and family eating habits, which may be important influences on children's sedentary, eating and emotional coping behaviors. In this sense, our results showed a relationship between low SES and internalizing problems that supports the effect of a family's low social and economic level on emotional status (Devenish, Hooley \& Mellor, 2017).

Looking at gender differences in our study, the female sex did not explain the relationship between emotional problems and obesity as has been shown by other studies with children (Erickson et al., 2000; Gibson et al., 2008) and adolescents (Mühlig et al., 2016).

According to the relationship between externalizing problems and obesity, we found that aggressive behavior was more frequent in obese children. These results are similar to those obtained by Griffits et al. (2011), who showed more conduct and peer relationship problems in obese 5-year-old boys.

However, Anderson, He, Schoppe-Sullivan, and Must, (2010) suggested that externalizing behaviors in early childhood were associated with higher BMI throughout the elementary school years, but they found that the magnitude of the effect was modest. Recently, Mallan et al. (2017) showed that among maternal-reported child eating behaviors, food responsiveness mediated the association between conduct problems and BMI z score. Therefore, we hypothesize that children with behavioral problems may be more likely to have a higher weight because they have less behavioral adjustment strategies and consequently, like other subjects with emotional distress, they eat impulsively.

We did not find a significant relationship between ADHD problems and obesity as has been found in recent years by other authors (Cortese \& Tessari, 2017; Khalife et al., 2014; Dahlgren and Björk, 2014; Griffits et al., 2011; Perez-Bonaventura et al., 2015). Several aspects could explain this lack of association; for instance, our study did not use specific tests for ADHD while other studies used ADHD patients or had a longitudinal design to explore the risk of one disorder on the other.

In conclusion, the results of this study support that in middle childhood there is a relationship between being overweight/obese and psychological problems, mainly internalizing problems, as well as a relationship between high BMI and BD. Since the simple mediational models were not significant, future studies should carry out mediational analyses with 
multiple mediators to assess this problem. However, the cross-sectional design of our study did not allow us to draw conclusions on the directionality between psychopathology and obesity. Another limitation of the study was the sample size because a high number of parents did not participate.

In Spain, there are few studies on obesity and psychological problems in children. The results of this study indicate that there is a relationship between obesity and psychopathology in school-aged children, which could affect the persistence and negative consequences of these two disorders. A multidisciplinary approach to obesity management that considers emotional troubles as well as other psychological and socio-family factors could be used to improve obesity prevention and treatment strategies.

\section{References}

Achenbach, T.M. \& Rescorla, L.A. (2001). Manual for the ASEBA School-Age Forms \& Profiles. Burlington, VT: University of Vermont, Research Center for Children, Youth, \& Families.

Al Mamun, A., Cramb, S., McDermott, B.M., O’Callaghan, M., Najman, J. M., \& Williams, G. M. (2007). Adolescents' perceived weight associated with depression in young adulthood: a longitudinal study. Obesity, 15, 3097-3105. doi: 10.1038/ oby.2007.369

Al-Agha, A. E., Al-Ghamdi, R. A., \& Halabi, S. A. (2016). Correlation between obesity and emotional, social, and behavioral problems associated with physical limitation among children and adolescents in Western Saudi Arabia. Saudi Medical Journal, 37, 161-165. doi: 10.15537/smj.2016.2.12953

Allen, K. L., Byrne, S. M., Blair, E. M. \& Davis, E. A. (2006). Why do some overweight children experience psychological problems? The role of weight and shape concern. International Journal of Pediatric Obesity, 1, 239-247

Anderson, S. E., Cohen, P., Naumova, E.N., \& Must, A. (2006). Association of depression and anxiety disorders with weight change in a prospective community-based study of children followed up into adulthood. Archives of Pediatrics and Adolescent Medicine, 160, 285-91. doi: 10.1001/archpedi.160.3.285

Anderson, S. E., He, X., Schoppe-Sullivan, S., \& Must, A. (2010). Externalizing behavior in early childhood and body mass index from age 2 to 12 years: longitudinal analyses of a prospective cohort study. BMC Pediatrics, 14, 10-49. doi: 10.1186/1471-2431-10-49

Aparicio, E., Canals, J., Voltas, N., Hernández-Martínez, C., \& Arija, V. (2013). Emotional psychopathology and increased adiposity: Follow-up study in adolescents. Journal of Adolescence, 36, 319-330. doi: 10.1016/j.adolescence.2012.12.003

Ask, H., Waaktaar, T., Seglem, K. B., \& Torgersen, S. (2016). Common etiological sources of anxiety, depression, and somatic complaints in adolescents: A multiple rater twin study. Journal of Abnormal Child Psychology, 44, 101-14. doi: 10.1007/s10802-015-9977-y
Babio, N., Arija, V., Sancho, C., \& Canals, J. (2008). Factors associated with body dissatisfaction in non-clinical adolescents at risk of eating disorders. Journal of Public Health, 16, 107-115

Belfer, M. L. (2008). Child and adolescent mental disorders: the magnitude of the problem across the globe. Journal of Child Psychology and Psychiatry, 49, 226-236. doi: 10.1111/j.1469-7610.2007.01855.x

Blaine, B. (2008). Does depression cause obesity? A meta-analysis of longitudinal studies of depression and weight control. Journal of Health Psychology, 13, 1190-1197. doi: $10.1177 / 1359105308095977$

Braet, C. (2005). Psychological profile to become and to stay obese. International Journal of Obesity, 29, 19-S23

Brands, B., Demmelmair, H., \& Koletzko, B. (2014). How growth due to infant nutrition influences obesity and later disease risk. Acta Paediatrica, 103, 578-585. doi: 10.1111/apa.12593

Brumpton, B., Langhammer, A., Romundstad, P., Chen, Y., \& Mai, X. M. (2013). The associations of anxiety and depression symptoms with weight change and incident obesity: The HUNT Study. International Journal of Obesity, 37, 12681274. doi: 10.1038/ijo.2012.204

Byrne, M. L., O’Brien-Simpson, N. M., Mitchell, S.A. \& Allen, N. B. (2015). Adolescent-onset depression: Are obesity and inflammation developmental mechanisms or outcomes? Child Psychiatry \& Human Development, 46, 839-850. doi: 10.1007/ s10578-014-0524-9

Burke, N. L. \& Storch, E. A. (2015). A meta-analysis of weight status and anxiety in children and adolescents. Journal of Development \& Behavioral Pediatrics, 36,133-145. doi: 10.1097/ DBP.0000000000000143

Campo, J. V. (2012). Annual Research Review: Functional somatic symptoms and associated anxiety and depression - developmental psychopathology in pediatric practice. Journal of Child Psychology and Psychiatry, 53, 575-592. doi: 10.1111/j.1469-7610.2012.02535.x

Cebolla, A., Baños, R. M., Botella, C., Lurbe, E., \& Torró, M. I. (2011). Perfil psicopatológico de niños con sobrepeso u obesidad en tratamiento de pérdida de peso. Revista de Psicopatología y Psicología Clínica, 16(2), 125-133. doi: 10.5944/rppc. vol.16.num.2.2011.10356

Chiang, P. H., Huang, L. Y., Lo, Y. T., Lee, M. S., \& Wahlqvist, M. L. (2013). Bidirectionality and gender differences in emotional disturbance associations with obesity among Taiwanese schoolchildren. Research in Developmental Disabilities, 34 , 3504-3516. doi: 10.1016/j.ridd.2013.06.023.

Chung, A., Backholer, K., Wong, E. Palermo, C. Keating, C., \& Peeters, A. (2016). Trends in child and adolescent obesity prevalence in economically advanced countries according to socioeconomic position: a systematic review. Obesity Reviews, 17, 276-295. doi: 10.1111/obr.12360.

Cole, T. J., Bellizzi, M. C., Flegal, K. M., \& Dietz, W. H. (2000). Establishing a standard definition for child overweight and obesity worldwide: international survey. British Medical Journal, 320, 1240-1243. doi: 10.1136/bmj.320.7244.1240

Cortese, S. \& Tessari, L. (2017) Attention-Deficit/Hyperactivity Disorder and Obesity: Update 2016. Current Psychiatry Reports, 14. doi: 10.1007/s11920-017-0754-1

Dahlgren, J. \& Björk, A. (2014). The importance of early screening and treatment of attention-deficit hyperactivity disorder 
in order to avoid morbid obesity in children. Acta Paediatrica, 103, 16-18. doi: 10.1111/apa.12427

Devenish, B., Hooley, M., \& Mellor, D. (2017). The Pathways between socioeconomic status and adolescent outcomes: A systematic review. American Journal of Community Psychology, 59, 219-238. doi: 10.1002/ajcp.12115

Doyle, A. C., Le Grange, D., Goldschmidt, A., \& Wilfley, D. E. (2007). Psychosocial and physical impairment in overweight adolescents at high risk for eating disorders. Obesity, 15, 145154

Drukker, M., Wojciechowski, F., Feron, F.J., Mengelers, R., \& Van Os, J. (2009). A community study of psychosocial functioning and weight in young children and adolescents. International Journal of Pediatric Obesity, 4, 91-97. doi: 10.1080/17477160802395442

Eckstein, K.C., Mikhail, L.M., Ariza, A.J., Thomsonc, J.S., Millardd, S.C., \& Binns, H.J. (2006). Parents' perceptions of their child's weight and health. Pediatrics, 117, 681-690

Erickson, S.J., Robinson, T.N., Haydel, K.F. \& Killen, J.D. (2000). Are overweight children unhappy? Body mass index, depressive symptoms, and overweight concerns in elementary school children. Archives of Pediatrics and Adolescent Medicine, 154, 931-935.

Esposito, M., Gallai, B., Roccella, M., Marotta, R., Lavano, F., Lavano, S. M., ... \& Carotenuto, M. (2014). Anxiety and depression levels in prepubertal obese children: a case-control study. Neuropsychiatric Disease and Treatment, 10, 18971902. doi: 10.2147/NDT.S69795

Faith, M. S., Butryn, M., Wadden, T. A., Fabricatore, A., Nguyen, A. M., \& Heymsfield, S. B. (2011). Evidence for prospective associations among depression and obesity in population-based studies. Obesity Reviews, 12, 438-453. doi: 10.1111/j.1467-789X.2010.00843.x

Freitas-Rosa, M., Goncalves, S., \& Antunes, H. (2013). The relationship between weight status and psychopathology in adolescence: The role of social support. Journal of Health Psychology, 19, 907-917. doi: 10.1177/1359105313482162

Gibson, L.Y., Byrne, S.M., Blair, E., Davis, E.A., Jacoby, P., \& Zubrick, S.R. (2008) Clustering of psychosocial symptoms in overweight children. Australian and New Zealand Journal of Psychiatry, 42, 118-125. doi: 10.1080/00048670701787560

Goldfield, G. S., Moore, C., Henderson, K., Buchholz, A., Obeid, N., \& Flament, M. F. (2010). Body dissatisfaction, dietary restraint, depression, and weight status in adolescents. Journal of School Health, 80, 186-192. doi: 10.1111/j.1746-1561.2009.00485.x

Grassi, T., De Donno, A., Bagordo, F., Serio, F., Piscitelli, P., Ceretti, E., ... \& Levorato, S. (2016). Socio-Economic and Environmental Factors Associated with Overweight and Obesity in Children Aged 6-8 Years Living in Five Italian Cities (the MAPEC_LIFE Cohort). International Journal of Environmental Research and Public Health, 13(10), 1002. doi: 10.3390/ijerph13101002

Griffiths, L. J., Dezateux, C., \& Hill, A. (2011). Is obesity associated with emotional and behavioural problems in children? Findings from the Millennium Cohort Study. International Journal of Pediatric Obesity, 6, 423-432. doi: 10.3109/17477166.2010.526221

Khalife, N., Kantomaa, M., Glover, V., Tammelin, T., Laitinen, J., Ebeling, H., ... \& Rodriguez, A. (2014). Childhood atten- tion-deficit/hyperactivity disorder symptoms are risk factors for obesity and physical inactivity in adolescence. Journal of the American Academy of Child \& Adolescent Psychiatry, 53(4), 425-436. doi: 10.1016/j.jaac.2014.01.009

Kieling, C., Baker-Henningham, H., Belfer, M., Conti, G., Ertem, I., Omigbodun, O., ... \& Rahman, A. (2011). Child and adolescent mental health worldwide: evidence for action. The Lancet, 378, 1515-1525. doi: 10.1016/S0140-6736(11)60827-1

Korczak, D.J., Lipman, E., Morrison, K., Duku, E., \& Szatmari, P. (2014). Child and adolescent psychopathology predicts increased adult body mass index: Results from a prospective community sample. Journal of Developmental \& Behavioral Pediatrics, 35, 108-117.doi: 10.1097/DBP.0000000000000015

Mallan K. M., Daniels L.A., \& Nicholson J. M. (2017). Obesogenic eating behaviors mediate the relationships between psychological problems and BMI in children. Obesity, 25, 928934. doi: 10.1002/oby.21823

Manios, Y. \& Costarelli, V. (2011). Childhood obesity in the WHO European region epidemiology of obesity in children and adolescents. Springer Series on Epidemiology and Public Health, 2, 43-68.

Mannan, M., Mamun, A., Doi, S., \& Clavarion, A. (2016). Prospective associations between depression and obesity for adolescent males and females-A systematic review and metanalysis of longitudinal studies. PlosOne, 11(6), e0157240. doi:10.1371/journal.pone.0157240.

Mond, J., van den Berg, P., Boutelle, K., Hannan, P., \& Neumark-Sztainer, D. (2011). Obesity, body dissatisfaction, and emotional well-being in early and late adolescence: Findings from the Project EAT Study. Journal of Adolescent Health, 48, 373-378. doi: 10.1016/j.jadohealth.2010.07.022.

Morrison, K.M., Shin, S., Tarnopolsky, M., \& Taylor, V.H. (2015). Association of depression \& health related quality of life with body composition in children and youth with obesity. Journal of Affective Disorders, 172, 18-23. doi: 10.1016/j. jad.2014.09.014

Mühlig, Y., Antel, J., Föcker, M., \& Hebebrand, J. (2016). Are bidirectional associations of obesity and depression already apparent in childhood and adolescence as based on high-quality studies? A systematic review. Obesity Review, 17, 235249. doi: 10.1111/obr.12357

Perez-Bonaventura, I., Granero, R., \& Ezpeleta, L. (2015). The relationship between weight status and emotional and behavioral problems in Spanish preschool children. Journal of Pediatric Psychology, 40, 455-463. doi:10.1093/jpepsy/jsu107

Pervanidou, P. \& Chrousos, G. P. (2011). Stress and obesity/metabolic syndrome in childhood and adolescence. International Journal of Pediatric Obesity, 6, 21-28. doi: 10.3109/17477166.2011.615996

Preacher, K. J. \& Hayes, A. F. (2008). Asymptotic and resampling strategies for assessing and comparing indirect effects in multiple mediator models. Behavior Research Methods, 40, 879891. doi: 10.3758/BRM.40.3.879

Rankin, J., Matthews, L., Cobley, S., Han, A., Sanders, R., Wiltshire, H.D., \& Baker J.S.

(2016). Psychological consequences of childhood obesity: psychiatric comorbidity and prevention. Adolescent Health, Medicine and Therapeutics, 16, 125-146. doi: 10.2147/AHMT. S101631 
Roberts, R.E. \& Duong, H.T. (2016). Do anxiety disorders play a role in adolescent obesity? Annals of Behavioral Medicine, 50, 613-621. doi: 10.1007/s12160-016-9786-8.

Robinson, S.M., Crozier, S.R., Harvey, N.C., Barton, B.D., Law, C.M., Godfrey, K.M., ... Inskip, H.M. (2015). Modifiable early-life risk factors for childhood adiposity and overweight: an analysis of their combined impact and potential for prevention. The American Journal of Clinical Nutrition, 101, 368375. doi: 10.3945/ajcn.114.094268.

Rofey, D. L., Kolko, R. P., Iosif, A. M., Silk, J. S., Bost, J. E., Feng, W., ... \& Dahl, R. E. (2009). A longitudinal study of childhood depression and anxiety in relation to weight gain. Child Psychiatry and Human Development, 40(4), 517-526. doi: 10.1007/s10578-009-0141-1.

Sawyer M. G., Miller-Lewis, L., Guy, S., Wake, M., Canterford, L., \& Carlin, W. (2006). Is there a relationship between overweight and obesity and mental health problems in 4-to 5-year-old Australian children? Ambulatory Pediatrics, 6, 306-311.

Segura, M., Roncero, M., Oltra-Cucarella, J., Blasco, L., Ciscar, S., Portillo, M., ... \& Perpiñá, C. (2017). Entrenamiento en remediación cognitiva y habilidades emocionales en formato grupal para pacientes con obesidad: Un estudio piloto. Revista de Psicopatología y Psicología Clínica, 22(2). doi: 10.5944/ rppc.vol.22.num.2.2017.19115

Seyedamini, B., Malek, A., Ebrahimi-Mameghani, M., \& Tajik, A. (2012). Correlation of obesity and overweight with emotional-behavioral problems in primary school age girls in Tabriz, Iran. Iranian Journal of Pediatrics, 22, 15-22.

Shanahan, L., Zucker, N., Copeland, W. E., Bondy, C. L., Egger, H. L., \& Costello, E. J. (2015). Childhood somatic complaints predict generalized anxiety and depressive disorders during young adulthood in a community sample. Psychological Medicine, 45, 1721-1730. doi: 10.1017/S0033291714002840

Spruijt-Metz, D. (2011). Etiology, treatment and prevention of obesity in childhood and adolescence: A decade in review. Journal of Research on Adolescence, 21, 129-152. doi: 10.1111/j.1532-7795.2010.00719.x

Tandon, P.S., Zhou, C., Sallis, J.F., Cain, K.L., Frank, L.D., \& and Saelens, B.E. (2012). Home environment relationships with children's physical activity, sedentary time, and screen time by socioeconomic status. International Journal of Behavioral Nutrition and Physical Activity, 9, 88. doi: 10.1186/14795868-9-88

Ter Bogt, T. F., Van Dorsselaer, S. A., Monshouwer, K., Verdurmen, J. E., Engels, R. C., \& Vollebergh, W. A. (2006). Body mass index and body weight perception as risk factors for internalizing and externalizing problem behavior among adolescents. Journal of Adolescence Health, 39, 27-34.

Tso, M., Rowland, B., Toumbourou, J. W., \& Guadagno, B. L. (2017). Overweight or obesity associations with physical aggression in children and adolescents. A meta-analysis International Journal of Behavioral Development. doi. org/10.1177/0165025417690265

Vámosi, M., Heitmann, B. L., \& Kyvik, K. O. (2010). The relation between an adverse psychological and social environment in childhood and the development of adult obesity: a systematic literature review. Obesity Reviews, 11, 177-184. doi: 10.1111/j.1467-789X.2009.00645.x

Van den Akker, K., Stewart, K., Antoniou, E.E., Palmberg, A., \& Jansen, A. (2014). Food cue reactivity, obesity, and impulsivity: Are they associated?. Current Addiction Reports, 1, 301308. doi: 10.1007/s40429-014-0038-3

Vannucci, A., Tanofsky-Kraff, M., Crosby, R. D., Ranzenhofer, L.M., Shomaker, L.B., Field, S.E., ... Yanovski, J.A. (2013). Latent profile analysis to determine the typology of disinhibited eating behaviors in children and adolescents. Journal of Consulting and Clinical Psychology, 81, 494-507. doi. org/10.1037/a0031209

Vila, G., Zipper, E., Dabbas, M., Bertrand, C., Robert, J. J., Ricour, C., \& Mouren-Siméoni, M. C. (2004). Mental disorders in obese children and adolescents. Psychosomatic Medicine, 66, 387-394.

Weinberger, N. A., Kerstingd, A., Riedel-Hellerb, S. G., \& Luck-Sikorskia, C. (2016). Body dissatisfaction in individuals with obesity compared to normal-weight individuals:

A systematic review and meta-analysis. Obesity Facts, 9, 424441. doi: 10.1159/000454837

Went, E., Björk, A. \& Dahlgren, J. (2017). Neurodevelopmental disorders are highly over-represented in children with obesity: A cross-sectional study. Obesity, 25. doi: 10.1002/oby.21693. 